\title{
El teatro de lo urbano en Santiago: Espacio público a fines de la Colonia
}

\author{
The urban context of Santiago: Public space at the end of the Colonial Period
}

<Resumen>

El espacio público, supuesto lugar de encuentro y participación, ha cambiado a lo largo de la historia de las ciudades. ¿Cómo se ha transformado en Santiago? Para responder a esta interrogante, hay que preguntarse en primer lugar cómo fue experimentado este espacio en el pasado. El siguiente artículo, fruto de la primera parte de una investigación doctoral, aborda la construcción de la noción de espacio público a fines de la Colonia en el casco antiguo de Santiago. Adoptando una perspectiva centrada en la dinámica de sus experimentaciones concretas, hemos trabajado con diversas fuentes documentales de la época relacionadas con este tema.

$<$ Abstract>

Public space, a place supposedly meant for both meeting and participation, has changed through the history of the city. How has it been transformed in Santiago de Chile? To answer this question, we must first ask ourselves how this place was experienced in the past. The next article, result of the first part of our doctoral research, addresses the generation of the notion of public space at the end of the colonial period in old downtown Santiago. Adopting a perspective based on the dynamics of its concrete subjective experiences, we have worked with several documental sources of the time related to this subject.

$<$ PALABRAS CLAVE $>$

ESPACIO PÚBLICO / CIUDAD DE SANTIAGO / ÉPOCA COLONIAL / ENCUENTRO Y PARTICIPACION

\section{$<K E Y W O R D S>$}

PUBLIC SPACE / CITY OF SANT IAGO / COLONIAL TIMES / MEET ING AND PARTICIPATION
El dieciocho de septiembre de 1810 marca el inicio de una nueva República en los confines de América. Si bien sabemos que aquel primer 18 no significó la declaración de Independencia, si abrió el camino a la vida independiente. Aquel día, un cabildo abierto votó por la formación de una junta de gobierno en suelo chileno, una junta independiente que, jurando fidelidad al capturado rey de España, sentaría las bases de un futuro autogobierno.

Ese día en la Plaza de Armas la gente se agolpó esperando saber el resultado de las discusiones del cabildo. Allí, en el corazón de la ciudad, vecinos expectantes palpitaron al ritmo de las voces en acuerdo y desacuerdo, haciendo suyo el escenario cotidiano de la vida común en la ciudad: el espacio público.
Doscientos años han pasado desde ese momento, sin embargo aquel espacio sigue allí. El centro de Santiago ha modificado su escenografía, pero el escenario es el mismo. Lo es desde que en 1541 Pedro de Valdivia decide fundar Santiago a los pies del Cerro Huelén estableciéndose la trama que tendría la ciudad.

Hoy, en pleno siglo xxI, en medio de fuertes tendencias que nos mueven hacia una "cultura global», se hace necesario, quizás más que nunca, preguntarse cómo llegamos a este punto. La pregunta necesita para ser contestada más de una mirada, más de una forma de concebir el mundo de lo social, de lo político, de lo económico y lo cultural. Si la infinidad de procesos exige infinidad de 
Plano de Fundación de Santiago, 1550-1590. Fuente: Dibujo de Emma de Ramón, en Armando de Ramón, Santiago de Chile (1541-1991) Historia de una sociedad urbana. Editoria

miradas, exige también infinidad de «objetos» de estudio. La ciudad, lo físico por excelencia, nos parece un perfecto marco de análisis, pues en sus formas, se expresa la diversidad a través del tiempo. En sus murallas, calles, plazas y edificios, se concentra y expande la historia, reflejando desde distintos ángulos la «realidad».

Es por esto que hacer un análisis de los espacios de la ciudad sin considerar su historia, es dar un salto al vacío, pues la genealogía no es un artilugio teórico que autores como Foucault utilizan porque suene bien. La historia reflexionada de los acontecimientos, los orígenes observados en perspectiva desde el presente, nos permiten entender mejor un momento actual. ¿Cómo podríamos entender el porqué de un espacio sin saber cómo era concebido antes? ¿Cómo mejorar lo existente sin conocer fracasos y éxitos anteriores?

Toda ciudad tiene una historia, una historia, única, intransferible, propia, y toda historia tiene un guión. Toda ciudad está formada de escenarios, de personajes y de la relación entre unos y otros. Existen variedad de protagonistas y sin lugar a dudas, variedad de actuaciones. Así las cosas, la cantidad de relaciones generadas entre éstos son incontables. Sin embargo, en el intento de relatar una historia, debemos centrar nuestra atención en ciertos aspectos, no podemos abordarlo todo, pues entonces nos transformaríamos en un «hombre reloj» que cuenta el paso del tiempo segundo a segundo, quedando sumergido en la extensión de la eternidad.

Es por esto que el presente artículo intentará contar una pequeña historia dentro de la totalidad de una saga, la historia de cómo fue entendido el "escenario más escénico» de la ciudad, el más expuesto, el más visto: el espacio público central de Santiago. Y por supuesto dentro de una época determinada, fines de la Colonia. La idea es entonces relatar cuál fue la concepción que se tuvo de éste, para que cuando observemos lo que

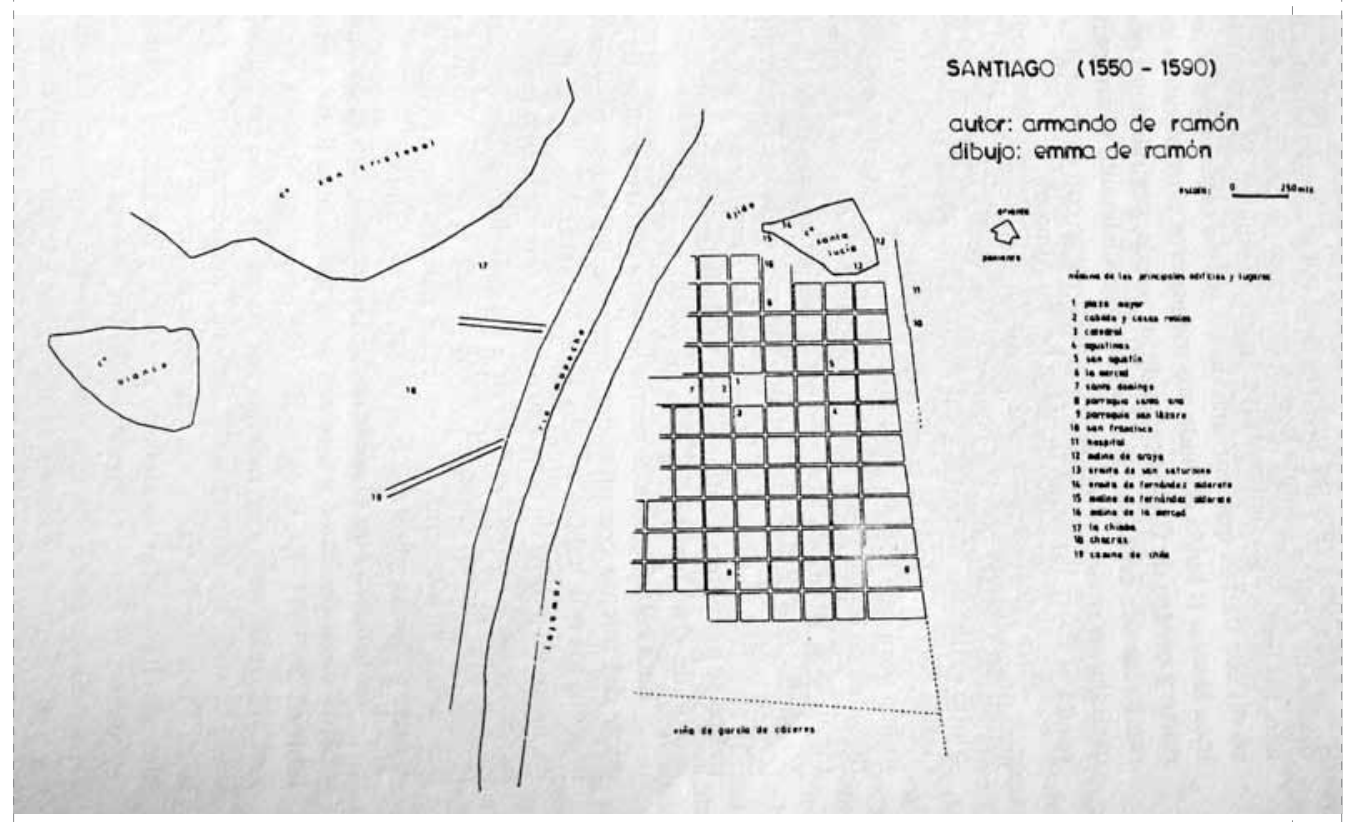

En esta imagen es posible observar que la ciudad de Santiago en sus primeras décadas de vida ocupaba una limitada porción de territorio, extendiéndose no más de 80 manzanas. Claramente para esa época, la Plaza Mayor, era el corazón de la ciudad, y las actividades se concentraban en esta zona y sus calles aledañas. 1. Plaza Mayor; 2. Cabildo y casas reales; 3. Catedral; 4. Agustinas; 5 . San Agustín; 6 La Merced; 7. Santo Domingo; 8. Parroquia Santa Ana; 9. Parroquia de San Lázaro; 10. San Francisco; 11. Hospital; 12. Molino de Araya; 13. Ermita de San Saturnino; 14. Ermita de Fernández Alderete; 15. Molino de Fernández Alderete; 16. Molino de la Merced: 17. L Chimba; 18. Chacras; 19. Camino de Chile.

hoy tenemos, sepamos cómo y hacia dónde cambió. La presente investigación, está inserta en un trabajo mayor que tiene por objetivo comparar -en tres momentos distintos de la llamada «modernidad»- las nociones de espacio público manejadas desde la oficialidad en el casco antiguo de Santiago de Chile ${ }^{1}$. En la reflexión que viene a continuación se resumirá la primera parte de esta historia, que vista en perspectiva, es el comienzo de la obra que vemos hoy, ya sea sentados en el palco o en la galería de esta ciudad.

\section{Espacio público a fines de la Colonia}

Para aproximarnos a la noción de espacio público de la época en cuestión, noción como tal inexistente, centramos nuestro trabajo en la revisión de una serie de documentos respecto a usos y reglamentaciones en la ciudad de Santiago a fines de la Colonia², y que afectarán de alguna u otra manera la utilización de los espacios públicos. Gracias a esta metodología se ha podido concluir que una primera entrada al tema de la

Para fines de esta investigación entenderemos por espacio público a aquellos lugares físicos que permiten el encuentro entre diversos grupos sociales, siendo la accesibilidad su principal característica.

2 Época que coincide con la llamada «primera modernidad». En este punto debemos aclarar que si bien la modernidad es un largo proceso vivido por las sociedades occidentales nosotros nos centraremos en su primera parte, aquella que se sitúa como forma de superación del antiguo régimen en Europa pero que evidentemente repercutirá en la vida hispanoamericana. Aquel proceso que pone en jaque al tradicionalismo monárquico y que es el marco en el que se desarrollarán las primeras repúblicas, hecho fundamental en Hispanoamérica ya que coincide con la época de las independencias.

Como principales características de esta modernidad se observan:

1. Irrupción del pueblo en la escena pública.

2. Progreso de las ideas y multiplicación de obras y autores

3. Nuevas formas de sociabilidad. Uno de sus principios básicos es el agruparse independientemente de la pertenencia a diferentes cuerpos o estamentos «de ahí se sigue que los vínculos son vistos como igualitarios, sin carácter personal y revocables, es decir como diferentes a los vínculos de tipo tradicional» (Guerra, 1992: 90). 
Santiago (1790) Rancheríos y Arrabales. Fuente: Dibujo de Emma de Ramón, en Armando de Ramón. Santiago de Chile (1541-1991) Historia de una sociedad urbana. Editorial Sudamericana, Santiago de Chile, 2000. Pág. 90

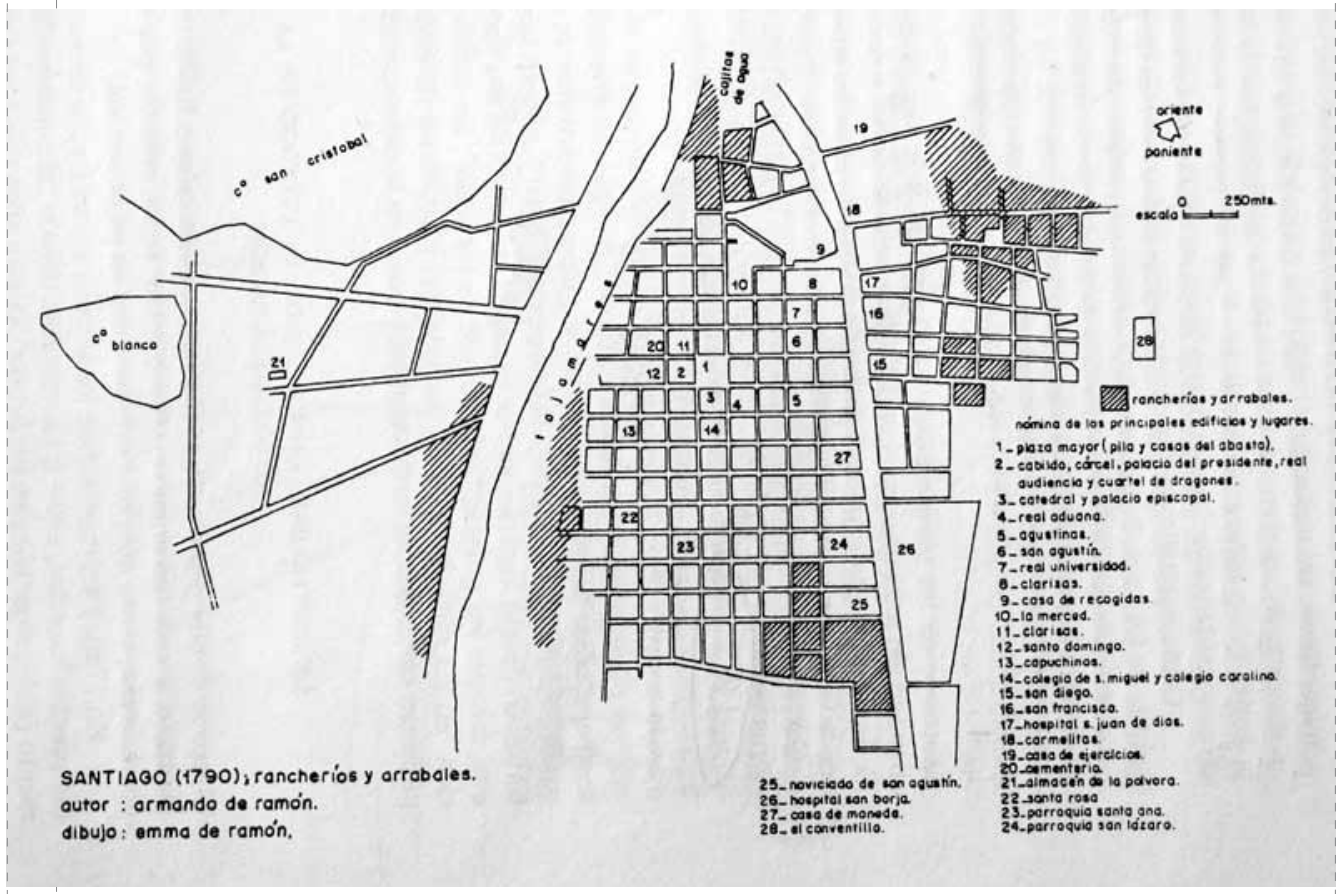

Hacia 1790, la ciudad no se había extendido mayormente, considerando el paso de dos largos siglos coloniales. Lo más relevante en este sentido fue el crecimiento de Santiago hacia el sur de «la Cañada». La construcción de esta última, será uno de los eventos más importantes en relación con la formación de nuevos espacios de uso público. 1. Plaza Mayor (pila y casas del abasto) 2. Cabildo, cárcel, Palacio del Presidente, Real Audiencia y Cuartel de Dragones; 3. Catedral y Palacio Episcopal; 4. Real Aduana; 5. Agustinas; 6. San Agustín; 7. Real Universidad; 8. Clarisas; 9. Casa de Recogidas; 10. La Merced: 11. Clarisas: 12. Santo Domingo: 13. Capuchinos: 14. Colegio de San Miguel y Colegio Carolino; 15. San Diego; 16. San Francisco; 17. Hospital San Juan de Dios; 18. Carmelitas; 19. Casa de Ejercicios, 20. Cementerio; 21. Almacén de la pólvora 22. Santa Rosa: 23. Рarroquia de Santa Ana: 24. Рarroquia San Lázaro. 25. Noviciado de San Agustín: 26. Hospital San Borja; 27: Casa de Moneda; 28. El conventillo.

conceptualización e imagen de los espacios públicos en esta época, se relaciona con la temática de la «seguridad y el control». En los documentos es posible observar que son dos los principales temas relacionados con este ámbito y que configuran la idea de espacio público: por un lado la importancia de la regulación del tiempo que ordenaba la vida y prácticas sociales de los habitantes de la época, y por otro, la importancia del control respecto a las conductas de los habitantes de la ciudad, especialmente de aquellos que se consideraban «peligrosos».

Estas dos variables, que penetran el espacio público, se establecen sobre dos realidades distintas. La primera de ellas, «el tiempo regulado", se establecía como una norma general, vale decir, sobre todos los habitantes de la ciudad, a diferencia de la segunda, de "control», que era ejercida sobre los pobres, los marginados, los «diferentes». Trataremos a fines de ella, se movía conforme a una atmósfera particular dominada por una regulación religiosa del tiempo. Como plantea Rojas Mix (1988), desde el nacimiento hasta la muerte, los ritos sociales estaban relacionados con los postulados ideológicos y la normativa ritual de la Iglesia, que de hecho organizaba la percepción que tenían los vecinos de la duración del día

" Al amanecer el Angelus [...] despertaba a la población con nueve regulares tañidos; a las veinte horas, el toque de ánimas anunciaba la llegada de la noche. Repiques especiales indicaban diversos sucesos públicos y privados» ${ }^{4}$.

Las iglesias se encontraban a escasas cuadras de distancia y compartían sus funciones con un número importante de capillas, conventos y monasterios. Serán estos edificios los que llevaran los repiques de sus campanas a todos los rincones de la ciudad, anunciando las distintas celebraciones litúrgicas y momentos de recogimiento y oración ${ }^{5}$.

Además de la existencia de las campanas que regulaban con sus sonidos el diario vivir y los ritmos de trabajo en la ciudad, existían también un par de relojes, uno de los cuales se encontraba en una de las torres frente a la plaza mayor. Este reloj fue por mucho tiempo el único existente, y cuando se descomponía, las horas se consideraban según el juicio subjetivo de algún vecino bien considerado para tal efecto. Así, a fines del siglo xvIII por ejemplo: Las autoridades del Cabildo: "acordaron que en virtud de hallarse de muchos años a esta parte totalmente descompuesto y en estado de perderse el reloj que se halla colocado en la torre de estas casas consistoriales, y pareciendo indispensable su compostura y refacción del lugar que ocupa para evitar en lo sucesivo de mayores gastos, el señor Procurador General de la Ciudad se presenta al Superior Gobierno para que se libren las providencias necesarias a este fin, sin perder de vista ser preciso en la apertura de algunas claraboyas para que el sonido de la campana lo sienta el público, con lo demás acordado sobre el particular»6.
Siguiendo a los diversos autores ${ }^{3}$ y fuentes revisadas, se puede sostener que la existencia privada y pública de los habitantes de la ciudad durante la época colonial y todavía
De Certeau, M. Foucault, M. Guerra, F.X. Habermas, J. Rojas Mix, M. Valenzuela, J.

Guarda, G. (1978). Historia urbana del Reino de Chile. Pág. 239

El sonido de la campana no era sólo anuncio de la duración del día, los oficios religiosos y los eventos vitales de los habitantes urbanos, sino también de los acontecimientos de la casa real y del imperio en general. Los súbditos entonces, en el rincón urbano en que se hallasen, estaban previamente informados de lo que acontecía a sus gobernantes. El lenguaje de las campanas era mucho mejor que un discurso racional, valía por sí mismo, no necesitaba de argumentaciones (Valenzuela, 1992: 238).

Cabildo 5 de junio de 1799 en Sociedad Chilena de Historia y Geografía. (1992). Actas del Cabildo de Santiago. Tomo LIX. Pág. 45 
Hacia fines de la Colonia, período que coincide con la supuesta llegada de la «modernidad» y sus ideas ilustradas, el tiempo medido y preciso, pasa a ocupar un lugar cada vez más central en la vida de la ciudad y por lo tanto de las prácticas en los espacios de uso público. Poco a poco, el tiempo de trabajo se irá sobreponiendo al tiempo religioso ${ }^{7}$. De hecho, cuando capitales extranjeros, descubren y explotan nuevos recursos naturales en Chile, se disciplina la mano de obra de acuerdo a las nuevas necesidades utilizando estos nuevos mecanismos de regulación temporal.

\section{Espacio público y el control sobre los «anormales»}

La segunda característica trabajada, tiene que ver con el control sobre lo diferente. Así, es posible observar la importancia que ocupaba «el miedo» entre los habitantes de la ciudad. En un principio, miedo a los indígenas de la zona -que representaban una amenaza constante a la consolidación de Santiago- y después, miedo a los pobres. Es por esto que el control y la seguridad han sido -y sonun tema central en esta sociedad urbana, tema que se relaciona con la organización del tiempo: Se pide que «del batallón de voluntarios se proporcionase una ronda desde las ocho de la noche hasta la una de la mañana, y otra hasta las seis; y que a la mayor brevedad se organicen los cuerpos cívicos para repartirse esta fatiga; siendo al mismo tiempo importante en las circunstancias se nombrasen dos alcaldes, de la Cañada hasta el Conventillo, y otros dos de la Chimba, que dependiendo del juez mayor de policía, cuiden de estos recintos y llenen todo el objeto de la seguridad pública» ${ }^{8}$

De hecho ya para 1804, el Cabildo de Santiago estableció la necesidad de crear un cuerpo de serenos que vigilaran por las noches las calles y demás lugares públicos de la ciudad a fin de evitar la serie de delitos que se cometían por aquel entonces, así como también espantar a las «almas en pena» $y$ «a veces al propio Satanás» (De Ramón, 2000).

Celebración de Pascua en la Alameda de las Delicias. Fuente: Guillermo Feliú Cruz, Santiago a comienzos del siglo xix. Crónicas de los Viajeros. Editorial Andrés Bello. Santiago, 2001. Pág. 349

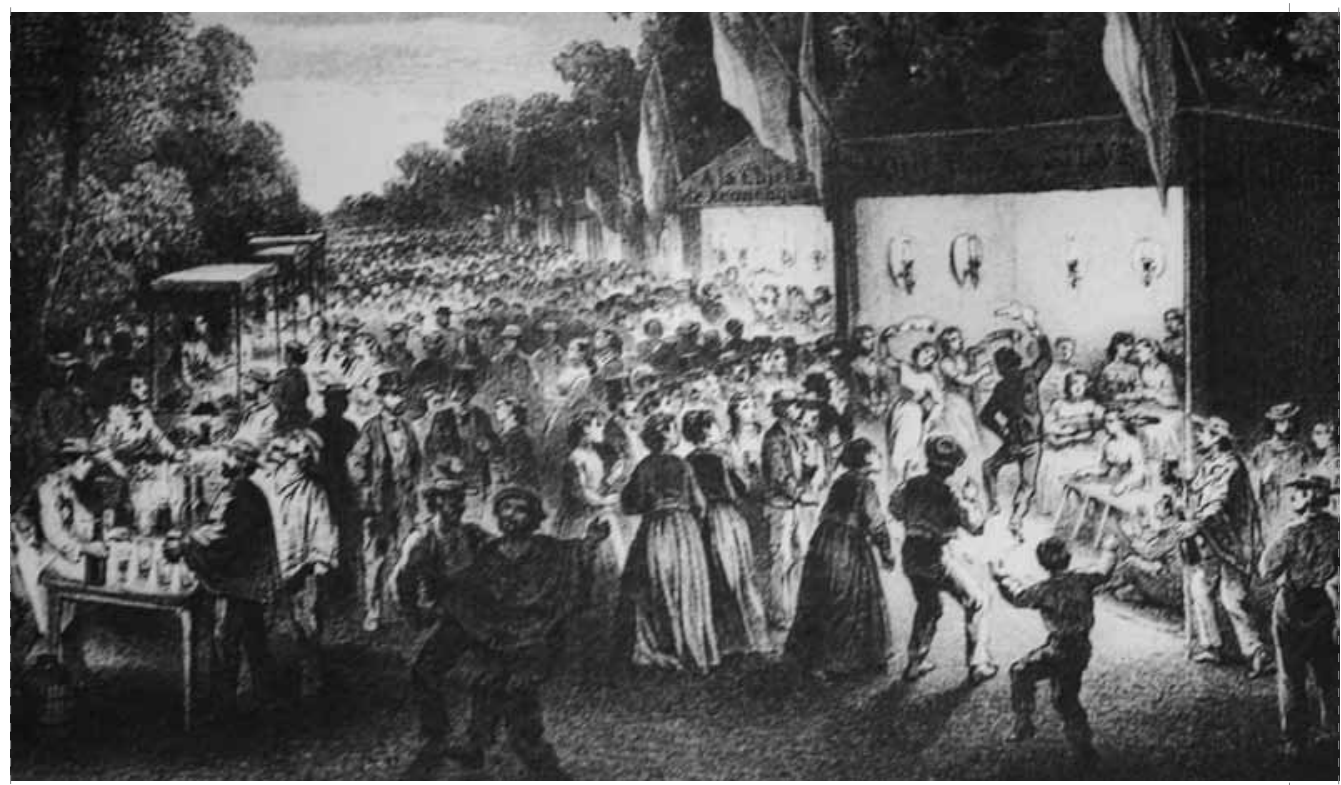

Puede apreciarse en esta imagen el carácter popular de las fiestas de fin de año en la Alameda. El pueblo alegre, bailarín, el «pueblo en fiesta», ocuparía este importante paseo para celebrar en fechas relevantes. Uno de los pocos momentos en que la representación de su uobra teatral» sería vista sin la censura habitual de la elite, aunque no sin crítica.

Ahora bien, es importante destacar que esta forma de organización no se relaciona sólo con la reglamentación del tiempo -al generar un ritmo de vigilancia-, sino también con la organización espacial. Este dato constituye, en la presente investigación, una de las principales características del espacio público a comienzos de la modernidad en Santiago de Chile: la fragmentación. ¿Por qué? Porque desde esta época es que el espacio de la ciudad comenzó a ser dividido y distinguido, a partir de sus características sociales ${ }^{9}$. Por este motivo, el centro, el casco histórico de la ciudad, comenzará también a fines del siglo XVIII y principios del siglo XIX, a vivir un proceso de remodelaciones para sacar del lugar «aquello indeseable». Una de las principales medidas tomadas será el traslado del tradicional mercado de la plaza ${ }^{10}$.
Se ha podido observar que si bien el espacio de uso público era uno solo, las reglamentaciones respecto a su uso, generaban prácticas diferentes según se tratara de uno u otro grupo social. Se sostiene de este modo, que la noción de espacio público manejada en la época respecto a este primer tema de entrada, era evidentemente de conflicto, hecho que se aleja de la ya clásica pero contemporánea visión que se maneja del espacio público como núcleo de convivencia social y participación pública ${ }^{11}$.

Recapitulando entonces, y considerando que la seguridad y el control son parte fundamental de los espacios públicos a fines de la época colonial, observamos que hay dos fenómenos importantes que se derivan de esta característica: la regulación del tiempo y el control sobre las actividades de la población.

Así, el nuevo sistema capitalista llegado junto a la llamada modernidad, impacta y se desarrolla rápidamente en el corazón mercantil y político de la nueva república. De la mano con sus requerimientos, también comienza a generalizarse la compulsión del horario exacto, la puntualidad de la producción y de su embarque, el cumplimiento de los contratos, etc. Es el tiempo burgués, homogéneo y artificial, extraño al ritmo cotidiano de la naturaleza, el que comienza a expandirse sobre los habitantes de la ciudad, armonizándolos cronológicamente al compás de los apremios capitalistas (Valenzuela, 1992).

Cabildo del 14 de abril de 1813 en Toribio Medina, J. (1910). Actas del Cabildo de Santiago. Tomo XXXIX. Pág. 213

"La situación de los sectores populares no podía ser más asfixiante. Condenados a vivir en arrabales miserables, constantemente vigilados por las autoridades, obligados a la infracción forzosa por falta de trabajo, aunque empujados a trabajar gratuitamente si eran sorprendidos en la más leve falta». Los pobres que mejor vivían eran los que «ejercían ficios de maestros y oficiales artesanos, y también los que se desempeñaban en el comercio ambulante en mercados y calles (de Ramón, 2000).

10 Un hecho fundamental en relación con la fragmentación espacial en Santiago fue la división de la ciudad en cuarteles a partir de 1778 . La ciudad se dividió en cuatro secciones, cada una bajo la responsabilidad de un alcalde. Cada sección fue regularizada fijando nombres para todas las calles y también una numeración para cada construcción. Tesis desarrollada extensamente por J. Habermas (1978). 
En relación con el primero, es necesario destacar que si bien durante la época colonial el tiempo era también regulado, esto se hacía en función de los ritmos religiosos, sin embargo ya hacia fines de la Colonia es posible ver que el tiempo será cada vez más regulado a partir de los horarios de trabajo, hecho que tendrá su representación física en el traspaso de la importancia del sonido de las campanas, a la instauración del reloj de un modo masivo. Se plantea entonces, que esta característica es influencia de las nuevas ideas traídas por la «modernidad» y representa la tendencia hacia la generalización de las conductas de la población en la ciudad, y por lo tanto una homogenización con relación al uso de los espacios públicos. La idea que hay detrás de este fenómeno sería la de la integración de los habitantes a un modelo de ciudad coordinado en función de tiempos útiles que involucran no sólo a la elite «moderna» gobernante, sino también al pueblo.

Sin embargo, se observa junto a este proceso un segundo, que si bien se vive de manera paralela al anterior, está en conflicto con éste: el control de las actividades de la población, que constituye el fenómeno más visible de la "seguridad y control». Este control se realiza directamente a través de la policía y genera una evidente especificidad de las conductas adecuadas de realizar en los espacios públicos, generando una constante exclusión de los grupos más «bajos» de la población [ESQUEMA 1].

ESQUEMA 1

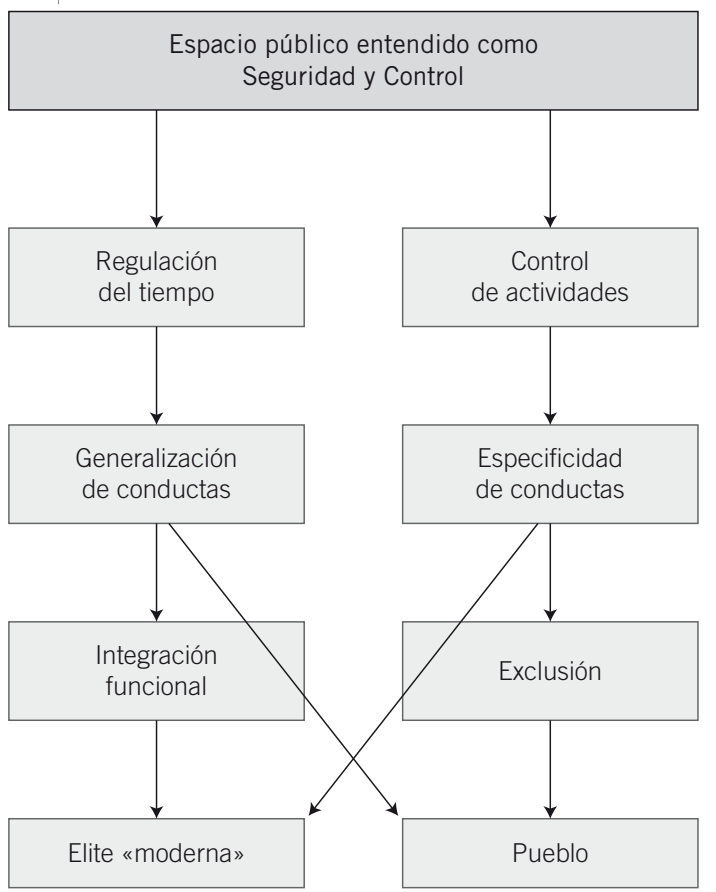

Como una segunda entrada respecto a la conformación y características del espacio público a fines de la Colonia en Santiago, complementaria a la problematización de la seguridad y el control, se encuentra la idea de «aseo y ornato», que se considera central en la preservación de los lugares de uso público. Este tema fue en general responsabilidad del Cabildo y determinó como consecuencia muchas de las prácticas dentro de los espacios urbanos. Ahora bien, tal como lo indica su nombre, este tema involucra dos problemáticas: en primer lugar la preocupación por la higiene de la ciudad y por la salud de sus habitantes, y en segundo lugar la preocupación por la ornamentación y decoración de la ciudad. Vale decir, el espacio público se concebía desde este punto de vista en base a dos dimensiones: una práctica (salud) y una estética.

\section{La importancia de la higiene en los espacios públicos}

Dentro del tema «aseo», la preocupación fundamental estaba dirigida hacia el aprovisionamiento de agua. Fue en la plaza central donde, durante toda la Colonia, se encontró la «pila de agua» oficial.

Sin embargo, hacia fines de la época colonial, se comienzan a observar en la ciudad una serie de nuevas construcciones que llevarán el agua hacia otros lugares, lo que nos muestra la aparición de la nueva idea de "progreso» desarrollada hacia fines del siglo xVIII y principios del $x \mathrm{X}^{12}$. Así, en el Cabildo del 6 de marzo de 1801 se acuerda que: "Vista la solicitud del señor Procurador General de la Ciudad, dirigida a que en atención a que se va a construir una pila de agua en la plazuela

Pila de agua en la Plaza de Armas de Santiago. Fuente: Fotografía maqueta de la Plaza de Armas Colonial del Museo Histórico Nacional. En: http://www.educarchile.cl

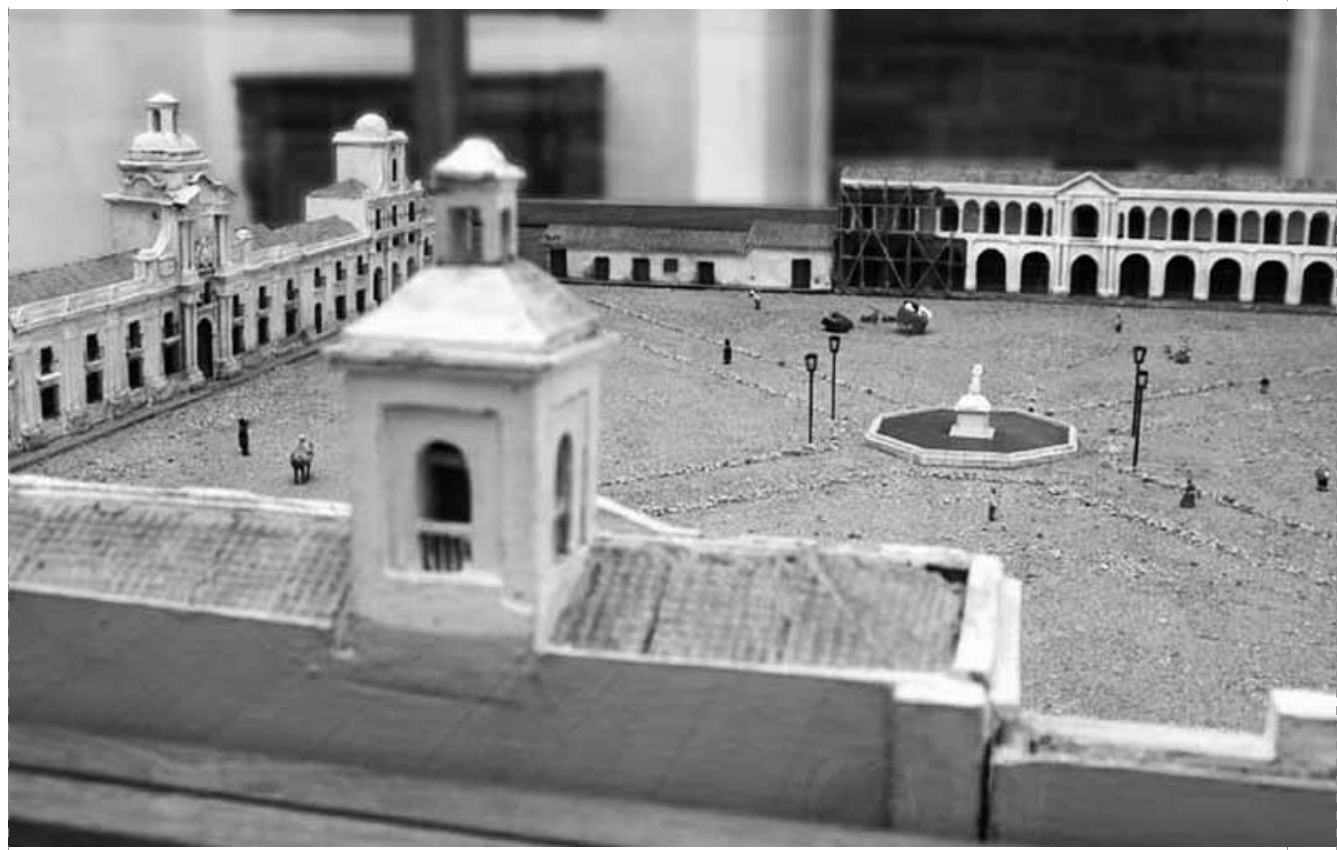

El agua fue durante muchos años el principal tema a resolver en términos de higiene y salubridad de la ciudad. No es casualidad que en el centro mismo del corazón de la ciudad se encontrara una pila de agua constituyéndose como uno de los ejes estructuradores del espacio público formado por la Plaza de Armas.

No sólo se trabajará el tema del agua en espacios públicos «clásicos», sino que comenzará también a desarrollarse una preocupación por la construcción de obras más importantes en términos de su extensión y complejidad, que afectarán las prácticas en los distintos espacios públicos. Al respecto destacamos la importante obra que significó la construcción del Canal San Carlos, un canal que uniría las aguas de los dos principales ríos de la zona, el Mapocho y el Maipo. 


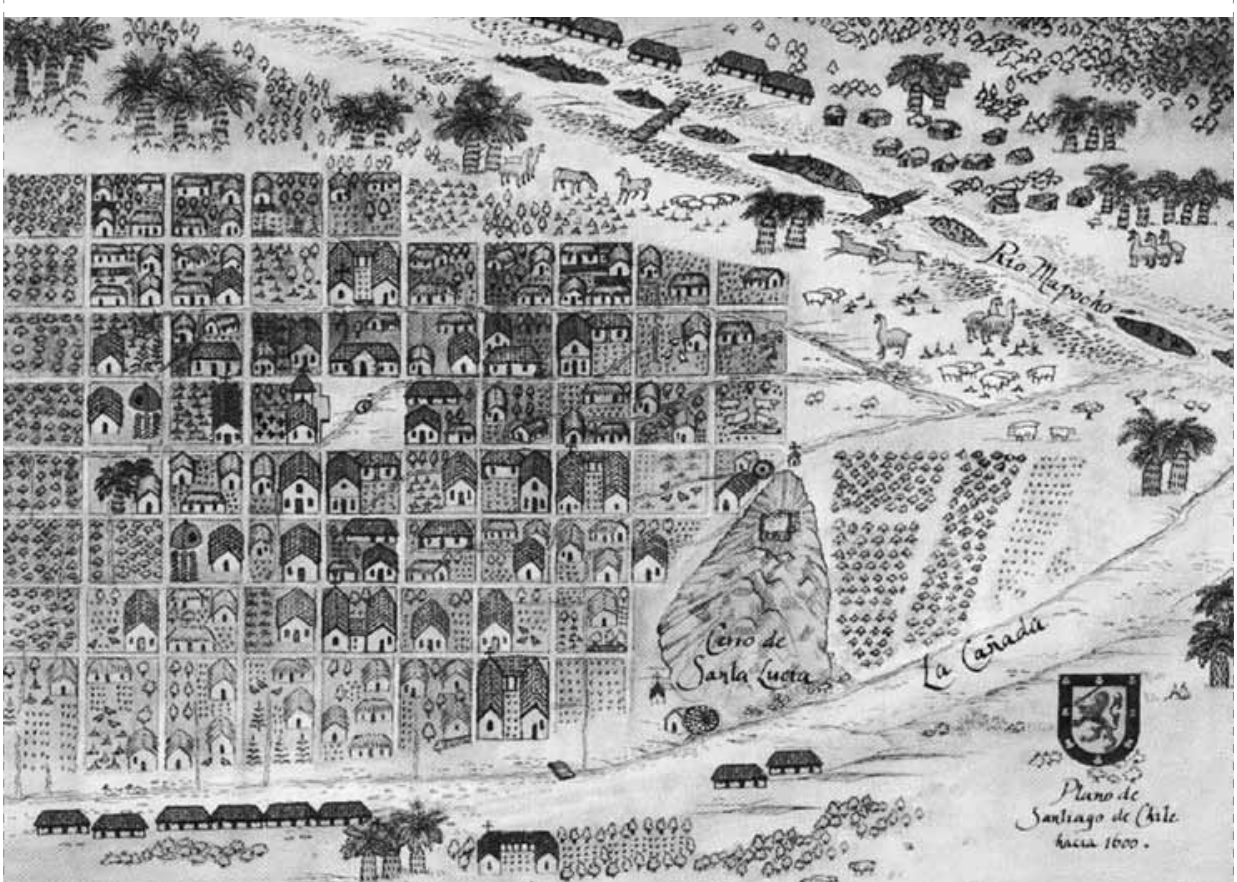

Llama la atención en este plano de Santiago de principios del siglo xvIl la especial atención que se le da al trazado de las acequias de la ciudad, que son dibujadas de modo destacado y sin una real relación con las demás dimensiones proyectadas. De

hecho, las acequias aparecen con un ancho equivalente al de la calle por donde pasan. dato que muestra la importancia que éstas tenían en la organización de la ciudad. muestra clara del papel central jugado por el agua en aquella época

de Santa Ana en cuya obra se está trabajando actualmente, se deje un pilón corriente en la medianía que hay antes de ésta y de la Plaza Mayor, y así mismo se refaccione la taza y pretil de esta última, que se hallasen corriente, derrumbada y rota: y acordaron que uno y otro pensamiento eran utilísimos e interesantes al público, y debían por lo tanto ponerse en ejecución, el primero no tanto por la necesidad cuanto atendiendo al poco costo que en las presentes circunstancias puede tener, y el segundo por ser esta pila la de primera atención y que debe remediarse ante todas por las razones que expone el señor Procurador»13.

...o el acuerdo del Cabildo del 28 de noviembre de 1806: "...y habiendo visto el expediente promovido sobre construir unas piletas para el abasto de agua limpia a los habitantes de la Cañada, en que con fecha de
18 del presente se ha comunicado traslado al señor Procurador General de Ciudad para que lo conteste con acuerdo del Cabildo» ${ }^{14}$.

Por otra parte, se aprecia también la importancia que seguían manteniendo las construcciones o arreglos sobre las pilas de agua o cañerías cercanas al centro histórico de la ciudad, tema que tocaba directamente con la organización de los espacios públicos, al ser justamente en éstos donde se encontraban los principales centros de abastecimiento de agua. Por ejemplo en acta del Cabildo de fecha 26 de noviembre de 1811 se establece que: "Habiendo el señor Procurador hecho presente a este Ilustre Cabildo lo muy maltratada que está la calle de las Monjitas, con motivo de las excavaciones que se hicieron para componer el cañón de la pila, mandaron dichos señores llamar al sota-síndico, y le ordenaron que a la mayor brevedad se pusiese en ejecución la compostura» ${ }^{15}$

Ahora bien, en relación directa con el tema de la higiene pública se pueden apreciar ciertos reglamentos como uno de 1803 que prohibió a las lavanderas lavar ropa y otras cosas cerca de los sitios públicos de la ciudad, pues acarreaban muchos desórdenes y lodazales. O la medida surgida a partir de la necesidad de construir baños públicos en la ciudad. De hecho en el acta del Cabildo de fecha 11 de febrero de 1803, se plantea que: "Dijeron que el señor Regidor Don Nicolás Matorras representó la necesidad que había de remediar el desaseo provenido de la libertad con que muchas personas hacen unas diligencias que aunque naturales y forzosas reserva el pudor y decencia para lugares ocultos, precisándolas a éstas la falta de proporciones que franquean en otros pueblos la figura de las casas y a que convida acá la soledad de algunas calles donde no hay vivientes que estorben este abuso tan indecente como incómodo a los que pasan por ellas o habitan en las inmediaciones; lo que a más es perjudicial a la salud, indecoroso a la Ciudad y que fomenta la impudencia tan contraria a las buenas costumbres, objetos todos de la atención de este Magistrado; propuso al mismo tiempo que para evitar este inconveniente se construyesen sobre las acequias que cortan las calles, donde se nota más tal inmundicia, unos lugares comunes que sin embarazar el tránsito ni poder servir a ocultar excesos, excusen la necesidad de infestar el suelo y el aire» ${ }^{16}$

$\mathrm{O}$ como se plantea en el artículo $\mathrm{N}^{\circ} 12$ y N ${ }^{\circ}$ 14 de un nuevo reglamento de policía creado en 1816: "No se permitirá por pretexto alguno, mantener abiertos los albañales inmundos que dan salida de sus aguas a las calles, ni que las hayan servido en lavados, se introduzcan en las acequias principales que dan bebida a la población, evitándose en éstas todo uso ajeno y contrario a su naturaleza... ${ }^{17}$.

"Ninguno podrá arrojar en las calles animales muertos, ni en sus acequias inmundicias o basuras. No se permitirá a los Artesanos sacar de sus talleres los desperdicios de sus obras, ni el que se pongan braseros fuera de ellos, ni que los menestrales se pongan en las veredas a hacer sus labores. No se consentirán las caballerías sueltas ni atadas en las esquinas, ni

\footnotetext{
13 Sociedad Chilena de Historia y Geografía. (1992). Actas del Cabildo de Santiago. Tomo LIX. Pág. 70

14 Sociedad Chilena de Historia y Geografía. (1992). Actas del Cabildo de Santiago. Tomo LIX. Pág. 166

Toribio Medina, J. (1910). Actas del Cabildo de Santiago. Tomo XXXIX. Pág. 148

16 Sociedad Chilena de Historia y Geografía. (1992). Actas del Cabildo de Santiago. Tomo LIX. Pág. 86

16 Sociedad Chilena de Historia y Geografía. (1992). Actas del Cabildo de Santiago. Tomo LIX. Pág. 86 (Art. N 12 Reglamento para la Policía, aseo y ornato de la Ciudad de Santiago. Santiago de Chile 2 de abril de 1816 Legajo Diversos 4 . Documentación del Virrey Abascal. 1816. Archivo de Indias de Sevilla).
} 
el que se ande a caballo por las enlosadas de las calles, bajo la pena los primeros de un peso por primera vez, y el duplo por la siguiente, y los segundos de perder las caballerías... ${ }^{18}$.

\section{Espacios públicos \\ en Santiago: \\ Su importancia estética}

Otro tema que se cree importante relevar, es el papel que se le otorga al componente estético de los espacios públicos, al "ornato», tema que será cada vez más importante respecto a las remodelaciones y nuevas construcciones que se realizan en Santiago. De hecho, el nuevo reglamento de policía anteriormente citado, dedica dos de sus artículos a este original tema: "No se permitirá la menor desproporción en las fábricas de casas que se construyan, que desfiguren el aspecto público, y si algún edificio o casas particulares amenazaren ruina, obligará a sus dueños a repararlas en el tiempo perentorio que se les asignará, y en el caso de no cumplirlo, lo sacará a público remate... ${ }^{19}$

Se aprecia de este modo, que la llegada de la «modernidad» marcará nuevas reglamentaciones respecto a los usos del espacio público en relación a la higiene principalmente, pero también con la estética que se consideraba como la adecuada. Así el tema aseo y ornato se presenta desde nuestro punto de vista, como la segunda entrada respecto a las características y visión del espacio público que se tenía a fines de la Colonia en Santiago.

Para retomar esta idea, lo primero que se destaca es que ambos temas -aseo y ornatoestán relacionados con la idea de progreso que se comienza a desarrollar hacia fines del siglo XVIII y principios del XIX que para ser llevada a cabo utilizará como mano de obra a las capas más «bajas» de la población. En este sentido el espacio público pasa a ser el escenario donde esta idea tendrá su representación física, y así tanto la idea de higiene como la de decoración son centrales en el fomento de una nueva ciudad acorde a los tiempos nacientes.

Ahora, si bien ambos aspectos del aseo y ornato tienden hacia el progreso de la ciudad, cada uno se relaciona con un aspecto diferente. Así, la higiene está relacionada con un fin práctico e interno a la ciudad ya que esta característica se relaciona con la salud de los habitantes. Al respecto se observa que el tema del «agua» se posiciona como central siendo el principal punto de conexión entre la idea de higiene y el espacio público. En este sentido es fundamental destacar que el desarrollo de nuevas técnicas constructivas, llevarán a una creciente privatización en los usos del agua, característica por cierto moderna20
Plaza de Armas hacia 1850 según Gillis. Fuente: Guillermo Feliú Cruz, Santiago a comienzos del sigloxix. Crónicas de lo Viajeros. Editorial Andrés Bello, Santiago, 2001. Pág. 333.

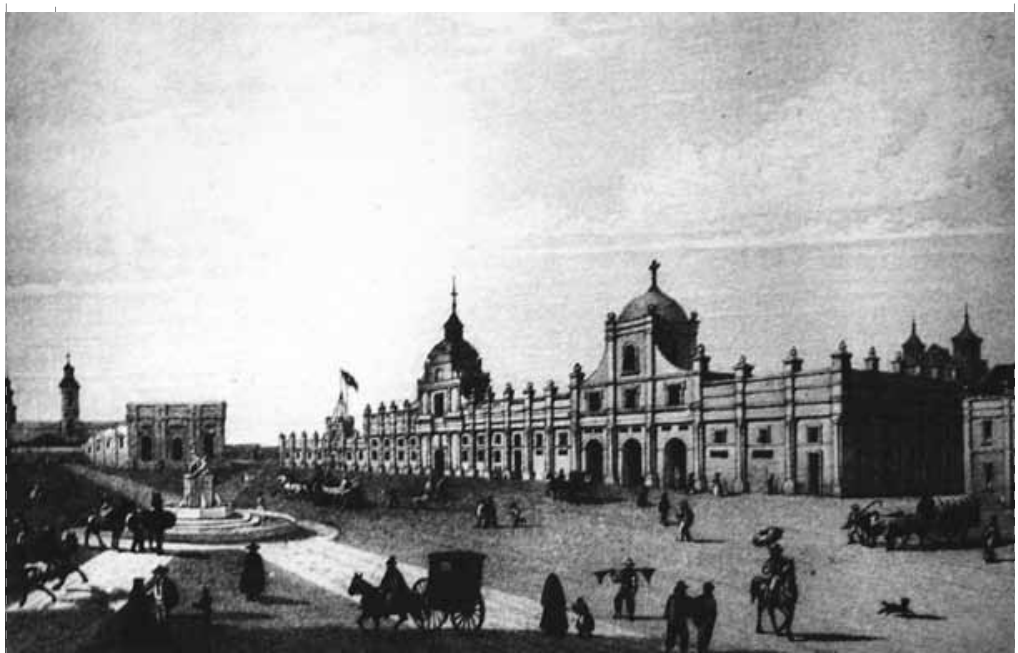

Observamos en este cuadro, la idea de amplitud asignada a la Plaza de Armas. La perspectiva que se nos ofrece, da cuenta del rol central de este espacio urbano, representado en esta imagen de un modo solemne y al mismo tiempo «bello».
Paseo de la Cañada a la altura del Convento de San Francisco. Fuente: Guillermo Feliú Cruz, Santiago a comienzos del siglo xix. Crónicas de los Viajeros. Editorial Andrés Bello, Santiago, 2001. Pág. 328

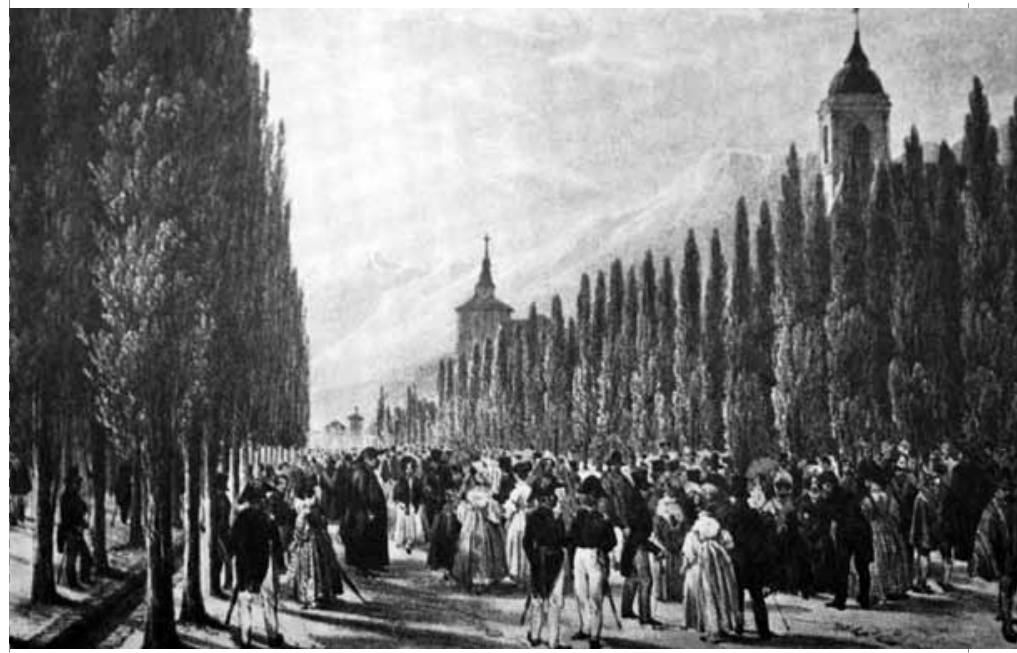

Esta imagen nos muestra la importancia que adquiriría el «paseo» en la constitución espacial de la ciudad. Noción que remite a una concepción no puramente práctica de la calle, y que desarrolla con fuerza una idea más estética de la ciudad, ligada al «ornato»y al esparcimiento.

18 (Art. N ${ }^{\circ} 14$ Reglamento para la Policía, aseo y ornato de la Ciudad de Santiago. Santiago de Chile 2 de abril de 1816 Legajo Diversos 4. Documentación del Virrey Abascal. 1816. Archivo de Indias de Sevilla).

19 (Art. N 20 Reglamento para la policía, aseo y ornato de la ciudad de Santiago. Santiago de Chile 2 de abril de 1816. Legajo diversos 4. Documentación del Virrey Abascal. 1816).

20 La existencia de pilas de agua en las principales plazas de la ciudad como característica colonial, será objeto de cambios con la llegada de la «modernidad» pues se comienzan a construir nuevas redes de agua que implican un cambio en la utilización de los espacios públicos al privatizarse cada vez más el uso de este recurso generándose espacios "alternativos». 
En relación con la decoración, subrayamos que si bien responde también a la nueva idea de progreso, se relaciona más bien con un fin estético que consideramos externo en la medida que plantea la necesidad de mostrar la ciudad hacia fuera ${ }^{21}$ [EsQuema 2].

ESQUEMA 2

Espacio público entendido como Aseo y Ornato

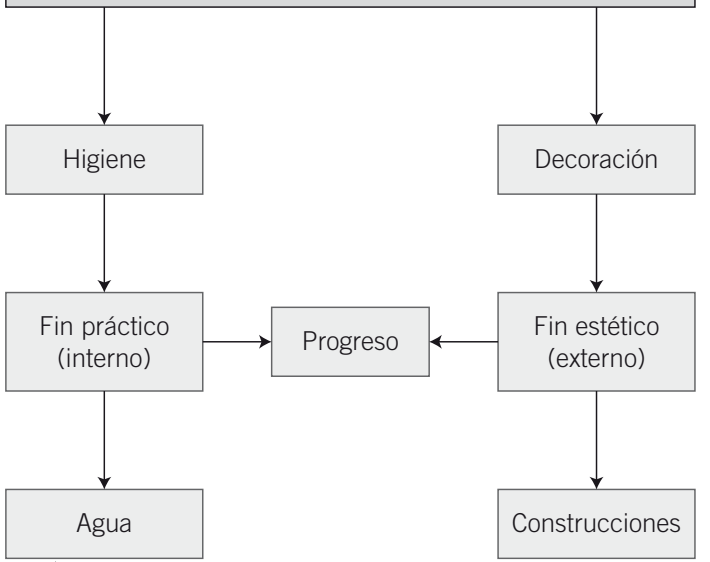

\section{Conclusiones}

Se puede observar que el espacio público a fines de la época colonial y desde la "oficialidad» es entendido como un espacio que debe ser protegido, protegido de lo malo, de lo insano, de lo feo. Esta perspectiva desarrolla un espacio segregado y nos muestra que si bien el escenario era uno solo este fenómeno se vivió a través de al menos dos realidades distintas y contradictorias: la vida pública de la elite, de los integrados, y la del pueblo, los excluidos.

Se concluye de este modo, que el espacio público estudiado puede ser analizado como un escenario donde se presentan «obras teatrales» paralelas, una llamada «Seguridad y Control» y la otra "Aseo y Ornato», lo interesante es que en ambas los personajes principales son los mismos: el pueblo y la elite.

Sin embargo, si leemos más detenidamente estos dos guiones, veremos que en realidad cada una de las dos obras engloba a su vez dos más: la de la integrada elite moderna con su idea de orden y progreso y la del pueblo excluido y vigilado constantemente por ser una amenaza a los nuevos ideales «modernos». Es decir, podemos observar al menos cuatro obras que son representadas a un mismo tiempo y en el mismo escenario. Y para complejizar aún más la situación, se observa que cada obra es vista por un determinado público, que varía dependiendo de la obra que esté viendo. De este modo, el pueblo que hace de público en las obras representadas por la elite, es quien observa desde la galería del teatro urbano las distintas prácticas sociales del grupo dirigente y su «puesta en escena». Así como al contrario, es la elite el público de las obras representadas por el pueblo, criticando desde el palco, su actuación. Podemos observar de este modo una «relación cruzada» entre actores y públicos que nos pone frente a la problemática del deseo oculto de ocupar el lugar del "otro», frente a la idea que el público no es sólo un espectador y que el actor también observa al público y de algún modo se reconoce en él.

"Le théâtre exige un spectateur actif, c'est-à dire qui a la responsabilité ultime de terminer la représentation : la scène n'est là que pour révéler le spectateur à lui-même». JACQUES LASSALLE $^{22}$.

Los años han pasado, y diversas obras han sido representadas en el «Teatro del Centro de Santiago». La elite, que vivió y recorrió esas calles, que compró en aquellas tiendas, que tomó de su agua, hoy vive retirada, lejos, muy lejos del casco antiguo. Pareciera ser que la «modernidad» y sus nuevos ideales, le hicieron ver que para progresar, debía huir de pueblo. Las ideas de control, de seguridad, de aseo y de ornato, impusieron sus reglas en el espacio público central, y lo transformaron en un lugar público pero «sin públicos», sin la heterogeneidad que se espera de un espacio accesible para todos.

El pueblo ha sido constantemente controlado, reprimido, pero sin embargo sigue allí, el centro dejó de ser el escenario de la elite para convertirse en el estrado del pueblo por excelencia: lustrabotas, vendedores ambulantes, artistas callejeros, pintores populares, predicadores, estudiantes de escuelas públicas, oficinistas. El exclusivo

${ }^{21}$ Este hecho se observa en la serie de construcciones que hacia fines del período colonial comienzan a desarrollarse en Santiago y que afectarán a los espacios públicos ya que involucran al tema decorativo en ellos además de generar nuevos espacios de uso público.

22 «El teatro exige un espectador activo, es decir que tenga la responsabilidad última de terminar la representación: el escenario no existe más que para revelar al espectador a sí mismo». Bretonnière, Bernard. Petit dictionnaire de théâtre. Editions THEATRALES. París, 2000. Pág. 106.

comercio que alguna vez existió en sus calles, se transformó en multitiendas de artículos de consumo masivo. La elite, dejada libre para desarrollar sus nuevos ideales, ya no vive en el centro, dejó hace mucho de experimentarlo. Las ideas modernas de libertad e igualdad, no tuvieron un correlato en los espacios públicos, al menos en Santiago. Y no porque éstos hayan dejado de serlo, sino porque la diversidad y alteridad, desaparecen día por día en un espacio cada vez menos compartido. Pareciera ser que los espacios públicos han devenido en espacios para públicos. ¿Cómo llegamos a este resultado? A responder esa interrogante se avoca la presente investigación doctoral.

\section{Referencias bibliográficas}

Bretonnière, B. «Petit dictionnaire de théâtre». Editions THEATRALES, París, 2000.

Centro de Estudios Históricos de Obras Públicas y Urbanismo. "La ciudad hispanoamericana: el sueño de un orden». Ediciones Ministerio de Fomento Secretaría Técnica. Centro de publicaciones, Madrid, 1997.

De Certeau, M. «L'invention du quotidien 1. Arts de faire». Gallimard, Paris, 1974

De Ramón, A. «Santiago de Chile (1541-1991). Historia de una sociedad urbana». Editorial Sudamericana, Santiago de Chile, 2000.

Feliú Cruz, G. «Santiago a comienzos del siglo xIx. Crónicas de los Viajeros». Editorial Andrés Bello, Santiago, 2001.

Foucault, M. «Surveiller et Punir». Editions Gallimard Paris, 1992.

Guerra, F.-X. «Modernidad e independencias. Ensayos sobre las revoluciones hispánicas». Editorial MAPFRE, Madrid, 1992.

Guerra, F.-X ; Lempérière, A. «Los espacios públicos en Iberoamérica. Ambigüedades y problemas». Fondo de Cultura Económica, México, 1998.

Guarda, G. «Historia urbana del reino de Chile». Editorial Andrés Bello, Santiago, 1998.

Habermas, Jürgen. «L'espace public. Archéologie de la Publicité comme dimension constitutive de la société bourgeoise». Payot, París, 1978.

Rojas Mix, M. «Un día en Santiago al terminar la época colonial». "La grande ville en Amérique Latine». C. Bataillon and J. Gilard. Editions du CNRS, París, 1988, Pág. 29-51.

Sociedad Chilena de Historia y Geografía. «Actas del Cabildo de Santiago. Tomo LIX». Sociedad Chilena de Historia y Geografía y Academia Chilena de la Historia, Santiago de Chile, 1992.

Toribio Medina, J. «Actas del Cabildo de Santiago. Tomo XXXIX». Santiago de Chile, 1910.

Valenzuela, J. (1992). «La percepción del tiempo en la colonia: poderes y sensibilidades.» Mapocho. Revista de Humanidades y Ciencia Sociales $N^{\circ}$ 32, 1992, pág. 225-244. 